\title{
Panorama da presença de populações humanas dentro dos Parques Nacionais brasileiros
}

\section{Overview of population presence within Brazilian National Parks}

Aline Francisco Damasceno, Gabriela Ferreira Mylonas, Eliana Cardoso-Leite

RESUMO: A presença de comunidades humanas nas Unidades de Conservação (UCs) é uma realidade em várias partes do território nacional, uma situação incompatível com a existência de áreas protegidas restritas. Este estudo analisou as comunidades humanas dentro dos Parques Nacionais Brasileiros. Os dados foram coletados por uma entrevista enviada aos gerentes dos Parques Nacionais com perguntas abertas. Os resultados forneceram informações sobre a relação entre comunidades humanas e a gestão do Parque Nacional. Os gerentes disseram que existem comunidades humanas em $58 \%$ dos Parques Nacionais e, destas, $69 \%$ são populações tradicionais. Portanto, quase $77 \%$ dos gestores consideram que as comunidades humanas causam impacto negativo na conservação, pois comunidades realizam ações contrárias à meta de conservação, como o uso direto de recursos naturais, caça, agricultura e desmatamento. Parte dos gerentes relata a existência de acordos formais ou informais com essas comunidades, que regulam sua permanência temporária na área, mas outros relatam que não há possibilidade ou interesse em estabelecer tais acordos, mostrando a existência de conflitos entre a gerência e as comunidades. A grande maioria dos gerentes percebe a presença de comunidades humanas como negativa nas UCs, afirmando que a solução seria realocar essas pessoas. Devido às dificuldades práticas e aos impactos sociais e culturais que eles podem causar, acredita-se que a maneira de minimizar esses conflitos possa ser o diálogo e o estabelecimento de pactos sociais que possibilitem a sobrevivência dessas comunidades e seus conhecimentos, bem como a conservação da natureza e da biodiversidade, que é o objetivo principal dos Parques Nacionais.

PALAVRAS CHAVE: Conflitos Socioambientais; Populações Tradicionais; Cogestão em Áreas Protegidas. 
ABSTRACT: The presence of human communities within the Protected Areas (PA) is a reality in various parts of the national territory, an incompatible situation with the existence of restrict protected areas. This study analyzed the human communities inside the Brazilian National Parks. The data collection gathered answers by one interview sent to National Parks managers with open question. The results provided information about the relationship between human communities and the management of National Parks. Overall, the managers answered that there are human communities inside $58 \%$ of National Parks, and of these $69 \%$ are traditional populations. Therefore, almost $77 \%$ of the managers considered that human communities cause negative impact to conservation, due to communities doing some actions that are against the goal of conservation, such as direct use of natural resources, hunting, agriculture and deforestation. Some managers even reported the existence of formal or informal agreements with these communities, which regulate their temporary stay in the area, but other managers report that there is no possibility or interest in establishing such agreements, showing the existence of conflicts between management and communities. The vast majority of managers perceive the presence of human communities as negative within the PAs, stating that the solution would be to relocate these people. Due to practical difficulties, and the social-cultural impacts that they could cause, a way to minimize these conflicts would be the dialogue and the establishment of social pacts that would enable the survival of these communities and their knowledge, as well as nature and biodiversity conservation, which is the primary goal of the National Parks.

KEYWORDS: Socio-Environmental Conflicts; Traditional Populations; CoManagement in Protected Areas.

\section{Introdução}

As Unidades de Conservação (UCs) são espaços territoriais criados para proteger parcelas significativas dos ecossistemas brasileiros e dos recursos naturais neles contidos, incluindo suas águas jurisdicionais, subsolo e espaço aéreo, e devem possuir limites bem definidos, além de seguir regimes especiais administrativos (BRASIL, 2000). Segundo dados da Protected Planet Report 2016, $14,7 \%$ da superfície continental do planeta está localizada no interior de áreas protegidas (ARNELL et al., 2016). No Brasil, somando-se todas as categorias de UCs, 15,06\% do território está legalmente protegido (PEREIRA et al., 2016).

As UCs brasileiras são regidas pelo conjunto de normas e critérios organizados na Lei no 9.985 de 18 de julho de 2000, dispostos no Sistema Nacional de Unidades de Conservação - SNUC (BRASIL, 2000). Esse sistema separa as Unidades de Conservação em doze categorias que se distinguem em objetivos, permissões e restrições, todas apresentando correspondentes ao modelo da União Internacional para Conservação da Natureza (IUCN). Dessas, cinco categorias são destinadas à proteção integral cuja finalidade é favorecer a manutenção dos ecossistemas, livres dos impactos das ações humanas e, as outras sete, ao uso sustentável, que devem compatibilizar a conservação com o uso de parcela dos seus recursos (Brasil, 2000). Todas as UCs federais são geridas pela autarquia federal do Instituto Chico Mendes de Conservação e da Biodiversidade (ICMBio) criado pela lei no 11.516, de 28 de agosto de 2007 (BRASIL, 2007). 
Entre as Unidades de Conservação de Proteção Integral (UCPIs) estão os Parques, que possuem equivalência à categoria II da IUCN, National Parks (DUDLEY, 2008). Os parques podem ser nacionais, estaduais ou municipais e têm como objetivo a preservação de ecossistemas naturais relevantes à conservação, mas também possibilitam atividades de uso público, educação ambiental e pesquisas, liberadas com aprovação prévia do gestor ou gestora. Seu conselho gestor deve ser consultivo e o plano de manejo deve ser aprovado e publicado pelo órgão gestor em um prazo de até cinco anos após a criação da Unidade de Conservação. Como uma unidade de conservação de proteção integral (UCPI), os parques são criados apenas pelo Estado, e a posse de terra deve ser pública. Nessa categoria não são permitidos moradores, sendo que a regularização fundiária é feita através de desapropriação (BRASIL, 2000). Nesse quesito, a categoria II da IUCN (National Park) difere da categoria Parque Nacional do SNUC, já que um de seus objetivos é manter a qualidade de vida das populações tradicionais e das comunidades residentes, garantindo a utilização de recursos para subsistência dessas (DUDLEY, 2008).

Diegues (2000) afirma que muitos Parques Nacionais possuem comunidades residentes e que muitas destas são consideradas tradicionais. $O$ decreto $\mathrm{n}^{\circ} \mathbf{6 . 0 4 0}$ de 07 de fevereiro de 2007 (BRASIL, 2007) define que populações tradicionais são: "grupos culturalmente diferenciados e que se reconhecem como tais, que possuem formas próprias de organização social, que ocupam e usam territórios e recursos naturais como condição para sua reprodução cultural, social, religiosa, ancestral e econômica, utilizando conhecimentos, inovações e práticas gerados e transmitidos pela tradição".

$\mathrm{Na}$ prática, a determinação de tradicionalidade é difícil de ser feita, já que trata de questões sociais complexas, sendo utilizados diversos critérios para o enquadramento de comunidades como tais. Diegues (2004) aponta onze características que auxiliam na compreensão dos conceitos envolvidos na singularidade das culturas e sociedades tradicionais, mas afirma que essas são baseadas em uma noção de tipo ideal e purista, ressaltando que não existem culturas nesse estado, pois cada uma dessas características possuem pesos diferentes para cada povo, além de que cada uma delas têm diferentes graus de articulação com o modo de vida capitalista.

Em Diegues e Arruda (2001) são listadas algumas das comunidades tradicionais identificadas tais como caboclos, caipiras, pescadores tradicionais, caiçaras, sertanejos, quilombolas e indígenas. Para Toledo e Barrera-Bassols (2015) o conceito de tradicionalidade é ainda mais amplo e deve incluir comunidades que utilizam tecnologias simples, que produzem ou extraem recursos naturais em pequena escala como pastores, caçadores, coletores, pescadores artesanais e pequenos agricultores. No SNUC (BRASIL, 2000), a tentativa de definir comunidades tradicionais no inciso XV do artigo 2o na mesma Lei é vetada, já que essa seria muito abrangente, ficando o conceito aberto ao se tratar de UCs.

Como não são permitidas comunidades humanas no interior de UCPIs, populações tradicionais residentes em áreas transformadas em UCs devem ser indenizadas ou compensadas e realocadas pelo Poder Público, conforme 0 artigo $42^{\circ}$ (BRASIL, 2000), o que concorda com o pensamento de autores preservacionistas como Terborgh et al. (2002) que acreditam que a conservação da biodiversidade só pode ser efetiva na ausência de pessoas residentes, pois suas práticas sempre causam impactos negativos no meio ambiente. 
No entanto, existem autores como Diegues (2004) que afirmam que a presença das populações tradicionais é essencial para uma conservação efetiva da natureza, pois elas possuem um conhecimento fundamental para o manejo da biodiversidade.

Outra visão é proposta por Ferreira (2004) que afirma ser mais importante saber se estas populações residentes podem ou não se tornar aliadas da conservação, salientando a importância de diálogos e pactos sociais entre os gestores, gestoras e as comunidades, de modo a promover uma conservação efetiva. Ainda segundo a autora, possibilitar o uso de áreas protegidas apenas por comunidades tradicionais, como defendido por Diegues (2004), restringe o direito a um grupo específico de habitantes e que a tradicionalidade é, muitas vezes, um conceito distorcido.

As questões envolvidas com a presença de comunidades no interior de UCs geram uma série de conflitos, principalmente em UCPIs (BRITO, 2000) e começam com a criação das primeiras unidades mundiais, já que estas foram idealizadas para servir como estoque de recursos naturais (DIEGUES, 2004), desconsiderando quaisquer necessidades das comunidades locais (BRITO, 2008).

É importante salientar que a recomendação internacional feita no IV Congresso Mundial de Parques, realizado em Caracas, Venezuela, é de que não sejam promovidos reassentamentos de populações tradicionais em casos de sobreposições em áreas protegidas, pois o sucesso das mesmas depende diretamente do apoio das comunidades (BRITO 2000; ARAUJO, 2007). Além disso, ao realizar reassentamentos também seria necessário definir quais comunidades seriam ou não reconhecidas como tradicionais e, ainda, tentar mensurar os impactos dessas sobre o meio ambiente (FRANCO, 2015).

Em geral, os conflitos ocasionados em UCs são relacionados à utilização dos recursos naturais, como incêndios, desmatamentos, práticas agropecuárias e afins, assim como a precária definição fundiária, a ausência de Planos de Manejo (PM) e de termos de compromisso (TC) entre a comunidade e a gestão (DRUMMOND; DIAS; BRITO, 2008). O Termo de Compromisso é definido como "instrumento de gestão e mediação de conflitos, de caráter transitório, a ser firmado entre o ICMBio e as populações tradicionais residentes em Unidades de Conservação onde a sua presença não seja admitida ou esteja em desacordo com os instrumentos de gestão, visando garantir a conservação da biodiversidade e as características socioeconômicas e culturais dos grupos sociais envolvidos" (BRASIL, 2012).

A discussão sobre a permanência de populações dentro de áreas protegidas, bem como a sua participação na conservação precisa ser debatida para a promoção do desenvolvimento sustentável. Desse modo, o presente artigo traz uma análise sobre a presença de populações dentro dos Parques Nacionais brasileiros (PARNAs) e a relação destas comunidades com a conservação.

\section{Metodologia}

Os dados apresentados neste trabalho são resultados de um questionário aberto que teve como objetivo analisar a presença de populações dentro dos limites dos Parques Nacionais, seu envolvimento nas atividades dos PARNAs e a visão da gestão sobre esta situação. 
Previamente, realizou-se uma revisão de literatura onde pudessem ser obtidos dados sobre presença de comunidades residentes nos Parques Nacionais Brasileiros, a origem das mesmas (se tradicionais ou não), e sobre existência de acordos entre a gestão dos Parques e as comunidades.

A coleta de dados primários foi feita por meio de um questionário que foi enviado aos endereços eletrônicos dos gestor(a)es de todos Parques Nacionais brasileiros com área continental, levantados nas bases de dados dos sites do Instituto Chico Mendes de Conservação e da Biodiversidade (ICMBio) e do Ministério do Meio Ambiente (MMA). Os mesmos foram respondidos pelos gestores(as) e devolvidos aos autores também via e-mail. A pesquisa ocorreu entre os meses de janeiro e março de 2017.

O questionário englobou três perguntas principais: 3- A população está envolvida com as atividades desenvolvidas na UC, tais como turismo, educação ambiental e outras? 2- Atualmente, o senhor(a) avalia que a presença da população é benéfica ou prejudicial para a conservação da UC? 3- Qual(is) motivo(s) o levam a considerar presença de população benéfica ou prejudicial?

Algumas perguntas auxiliares também foram feitas, de modo a subsidiar a discussão dos dados do levantamento bibliográfico, sendo: a- O Parque tem comunidades residentes? b- São populações tradicionais? c- Se tradicionais, de quais etnias? d- Existem acordos formais ou informais com as comunidades residentes, que normatizam sua permanência temporária dentro da UC?

Dos três PARNAs Marinhos, apenas o PARNA Marinho Fernando de Noronha foi incluído na pesquisa por ser o único a apresentar área terrestre. Dos 70 Parques Nacionais considerados na pesquisa, somente um não recebeu o questionário por não possuir endereço eletrônico divulgado.

Para a análise dos dados, foi feita uma triagem das respostas obtidas e calculada a frequência em que essas apareciam, gerando gráficos para uma melhor visualização e comparação dos resultados, através das porcentagens obtidas.

\section{Resultados e Discussão}

\section{Dados secundários}

Em diagnóstico feito por Madeira et al. (2015) intitulado "Interfaces Territoriais entre Unidades de Conservação e Povos e Comunidades Tradicionais" realizado em 2013 e 2014 53(76,8\%) do PARNAs analisados possuíam ao menos uma comunidade que residiam ou utilizavam recursos da área.

Segundo os dados de Madeira et al. (2015) em uma mesma UC pode ocorrer um ou mais agrupamentos humanos, sendo de um mesmo grupo social ou de distintos grupos sociais. Os autores registraram 81 grupos sociais dentro de 53 PARNAs, sendo estes grupos principalmente compostos por populações tradicionais das etnias indígena e quilombola, além de agricultores familiares e assentados de reforma agrária. A presença de comunidades em Unidades de Proteção Integral é considerada uma das maiores dificuldades relacionadas à gestão dessas áreas, já que esse tipo de UC prevê que a área não seja manejada ou sirva de território de comunidades, representando uma série de conflitos de interesses (DIEGUES, 2000; ARRUDA, 1999). 
Em relação a existência ou não do Plano de Manejo (PM), Madeira et al. (2015) registraram que 35 PARNAs possuíam essa ferramenta de gestão, porém, apenas 15 abordavam as comunidades e indicavam uma solução para a presença delas, sendo 12 deles uma solução negociada e 3 uma solução unilateral, ou seja, não acordada com o grupo social. Outra análise feita por Madeira et al. (2015), foi o levantamento da demanda pela celebração de TC (Termos de Compromisso) ou instrumentos semelhantes que visavam viabilizar uma convivência harmônica entre as comunidades e a gestão. Segundo os autores, existiam apenas $3 \mathrm{TC}$ em implementação nos PARNAs e 12 em elaboração ou negociação.

\section{Respostas dos gestores}

Sobre a presença de comunidades no PARNAs os gestores afirmaram que há presença de comunidades em $58 \%$ das áreas, sendo que destas $69 \%$ são populações tradicionais, principalmente das etnias quilombola, indígena e ribeirinha. Estes resultados concordam com os de Madeira et al. (2015) e mostram que a situação da presença de pessoas nos PARNAs continua a existir.

Em relação ao impacto da presença das comunidades nos PARNAs, 77,3\% dos gestores(as) avaliaram a presença das mesmas como prejudicial para a conservação (Figura 1). Apenas $9,1 \%$ (2) dos gestores(as) consideram que as comunidades auxiliam no monitoramento da UC e por isso, a presença dessas pode ser considerada benéfica. Outros $13,6 \%$ acreditam que a presença também é favorável por auxiliarem no monitoramento, gestão e turismo, mas que elas realizam algumas atividades incompatíveis com os objetivos das UCs.

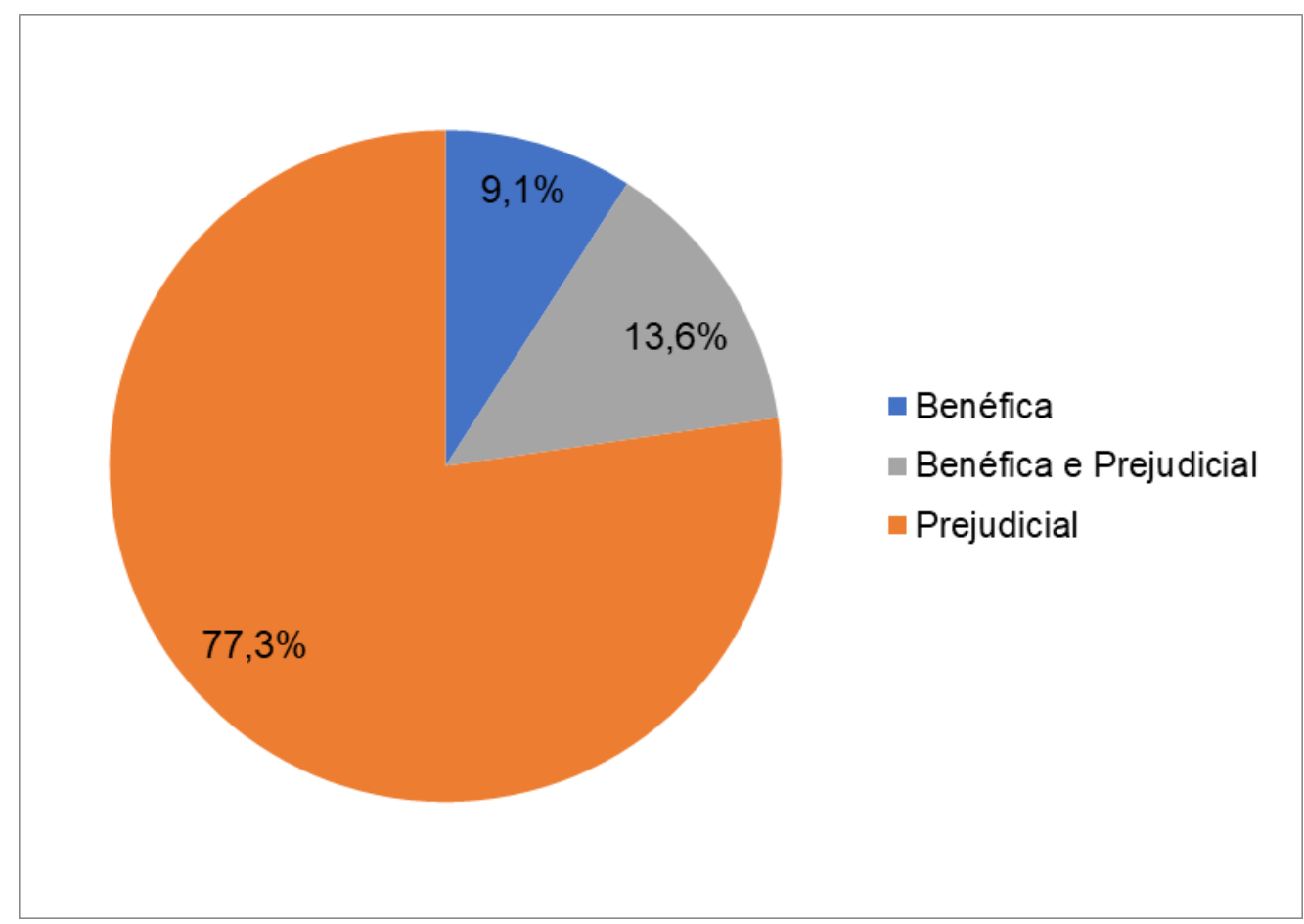

Figura 1: Avaliação dos gestores sobre os impactos causados pelas comunidades dentro dos Parques Nacionais.

Figure 1: Manager's evaluation about impact caused by human communities inside National Parks. 
Os principais motivos apresentados pelos gestores(as) que acreditam que a presença de comunidades prejudica a conservação é o uso direto dos recursos, a criação de animais, incêndios, habitação, entre outros (Figura 2), o que indica que os mesmos apresentam uma visão de conservação focada no paradigma preservacionista (REDFORD; RICHTER, 2001; Terborgh et al. 2002) o qual tem como pressuposto que a conservação da biodiversidade só é efetiva se for restritiva, ou seja, se não houver presença humana nas áreas protegidas.

Desta forma, a maioria dos gestores(as) concorda como SNUC (2000), indicando como caminho para resolução da problemática a retirada das populações residentes de dentro da área da UC, o que envolve a realocação e a indenização das mesmas. No entanto, como já evidenciado por Diegues (2000) estes deslocamentos além de representarem um gasto para o Estado, poderiam originar outros novos conflitos.

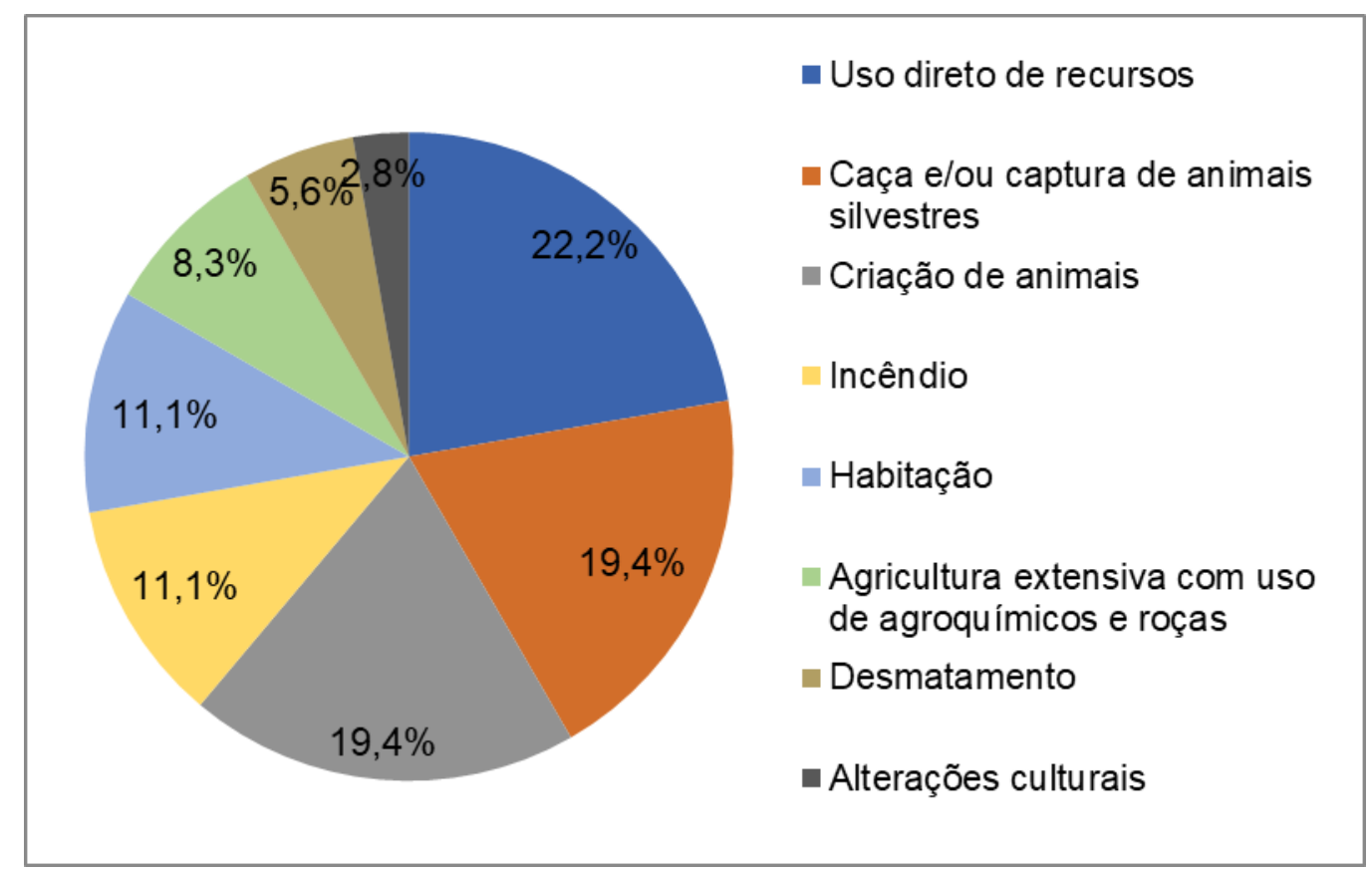

Figura 2: Motivos pelos quais os(as) gestores(as) consideram a presença de populações prejudicial à conservação.

Figure 2: Reasons why managers consider the presence of populations harmful to conservation.

No presente estudo, quando questionados sobre a possibilidade de acordos para manutenção temporária (ou não) das populações tradicionais dentro da área dos PARNAs aproximadamente metade dos gestores respondeu que existem acordos informais ou estão em andamento acordos formais, e outra metade respondeu que não existe e não há interesse ou possibilidade de estabelecer esses acordos. Um dos gestores afirmou que o estabelecimento de acordos é questionável pois ao mesmo tempo que representa uma ferramenta de normatização, poderia representar um prazo (máximo) para realocação das comunidades, o que não seria desejável, pois o ideal seria realocar estas comunidades 0 mais rapidamente possível.

Quando questionados sobre o envolvimento das comunidades nas atividades desenvolvidas dentro dos PARNAs, os gestores(as) afirmaram que as comunidades estão envolvidas em $59,1 \%$ dos casos, e em $27,3 \%$ parcialmente envolvidas (Figura 
3), registrando também que esse envolvimento está relacionado principalmente ao turismo e a participação no Conselho Consultivo. Gestores(as) de dois PARNAS (Figura 3) informaram que as comunidades estão pouco envolvidas nas atividades da UC, pelo fato de não haver visitação dentro do local onde elas residem. Outro gestor, mencionou que apresenta uma situação semelhante devido à falta de publicação do Plano de Manejo. E por fim, um gestor apontou que o pouco envolvimento das comunidades se dá pela existência de conflitos com a gestão.

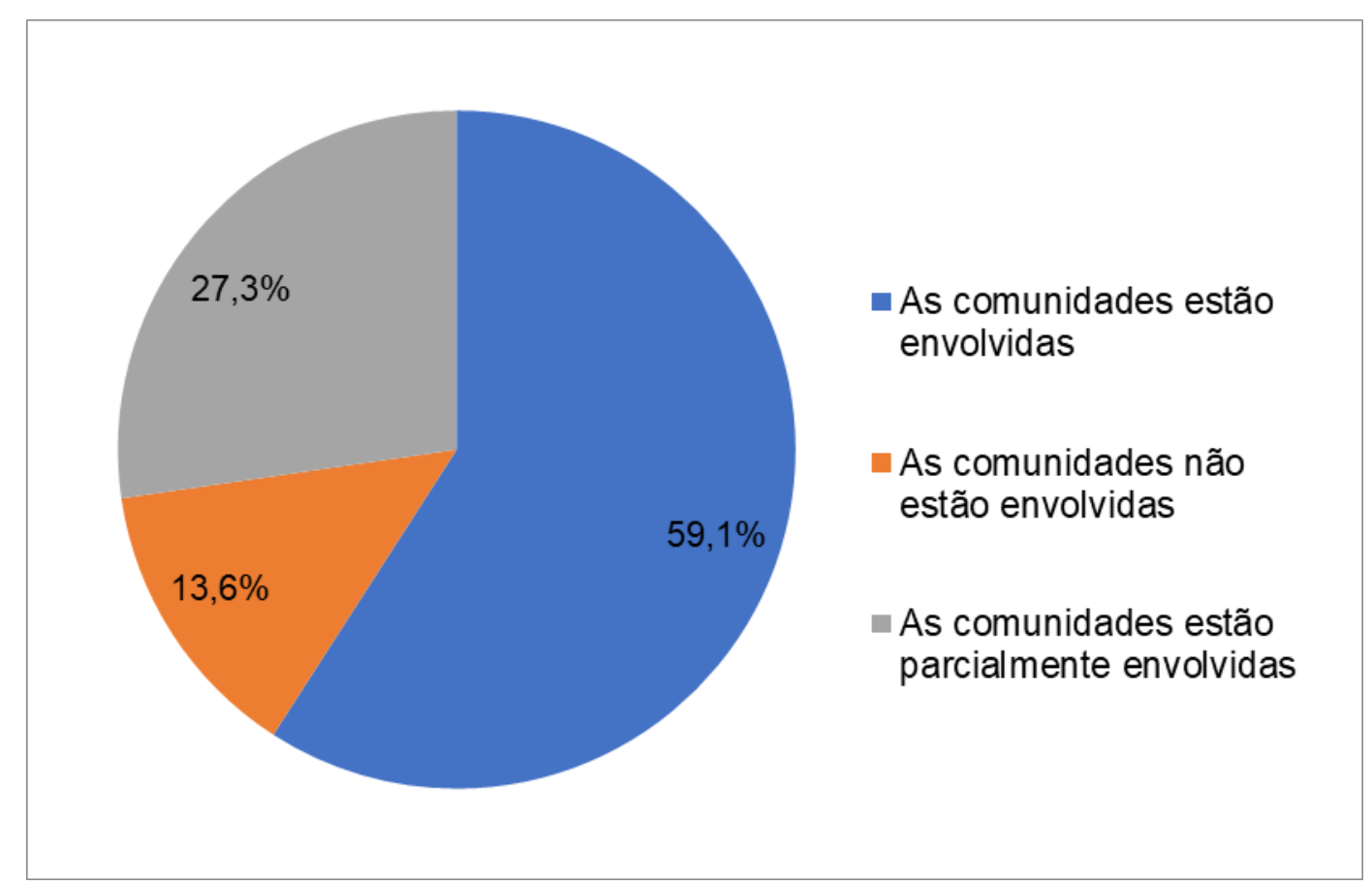

Figura 3: Porcentagem de respostas dos(as) gestores(as) e gestoras sobre o envolvimento das comunidades na UC.

Figure 3: Proportion of manager's answers on the involvement of communities in the PA.

\section{O dilema entre realocar ou integrar pessoas nas áreas protegidas}

Os resultados evidenciam que a maioria dos gestores percebe a presença de comunidades nos PARNAs como algo negativo (Figura 1) pois, segundo a maioria dos gestores(as) a ação destas comunidades causa danos à Natureza como extração de espécies, desmatamento e outros (Figura 2). Portanto, fica clara a existência de conflito entre a gestão dos PARNAs e as comunidades humanas residentes nos mesmos, e segundo os(as) gestores(as) a solução deste conflito seria o caminho legal (BRASIL, 2000) ou seja, a realocação destas pessoas para fora da área dos PARNAs, que é baseado no paradigma de conservação preservacionista (REDFORD; RICHTER, 2001; TERBORGH et al. 2002).

A realocação de pessoas é complexa, pois por um lado envolve custo financeiros por parte do Estado que seria o responsável por promover a retirada das pessoas e sua realocação em outros locais. Por outro lado, existem custos sociais e culturais para as comunidades. Deve-se levar em consideração que as comunidades tradicionais possuem uma forte relação sociocultural com o território, de modo que este abriga todas as suas dimensões sociais, culturais e políticas, além de valores simbólicos e afetivos (SILVA PIMENTEL; RIBEIRO 2016). Little (2002) afirma que a 
territorialidade é importante para a construção do conceito de populações tradicionais, já que as pessoas possuem uma memória coletiva sobre a história de ocupação, um sentido comum de propriedade e um sentimento de pertencimento a um lugar específico. Para Silva Pimentel e Ribeiro (2016), realocar comunidades não é simplesmente promover uma desocupação espacial de povos, mas sim realizar uma desterritorialização sociocultural, ideia defendida também por AvellanedaTorres et al. (2015).

Além disso, autores como Diegues (2000) e Oliveira (2004) acreditam que as populações tradicionais são componentes sociais de suma importância para a manutenção de áreas protegidas, apresentando um conhecimento tradicional secular da biodiversidade (Pereira e Diegues, 2010) que é fundamental para a conservação das mesmas. Toledo e Barrera-Barsols (2015) enfatizam também que a memória biocultural, ou seja, o conhecimento das pessoas sobre a Natureza é essencial para manutenção da cultura dessas comunidades e dos ecossistemas onde elas vivem.

Embora a maioria dos gestores perceba a presença de pessoas como algo negativo (Figura 1) os mesmos afirmam que as comunidades residentes ou do entorno se envolvem (na maioria dos casos) com as atividades do Parque (Figura 3), no entanto este envolvimento se dá via atividades do Conselho Consultivo ou de atividades ligadas ao ecoturismo. Isso indica que a gestão dessas unidades enxerga na atividade turística (e somente nesta) uma possibilidade de "integração" das comunidades com a gestão dos PARNAs. Isto concorda com a visão de diversos autores que apontam o turismo como uma das possibilidades para viabilizar a inclusão social das populações tradicionais em áreas protegidas por proporcionar geração de renda (CAMPOLIM et al., 2008; SILVEIRA-JUNIOR; BOTELHO, 2011) e por ser considerada uma atividade de baixo impacto (CAMPOLIM et al., 2008) conseguindo harmonizar a presença de comunidades tradicionais e os objetivos da UC.

No entanto, a aposta no ecoturismo ou turismo como única estratégia de conciliar a presença de pessoas dentro de áreas de proteção integral pode apresentar problemas (ALVAIDES,2013). O estudo (ALVAIDES, 2013) realizado com a comunidade Marujá no Parque Estadual da llha do Cardoso, mostrou que com o abandono gradual das práticas agrícolas, com o aumento do comércio dos bens da pesca e com o incremento do fluxo e renda do turismo, as memórias sobre as práticas de manejo de recursos naturais vão se perdendo ao longo do tempo, e neste processo, pode haver o risco da extinção da cultura e transmutação da identidade de uma forma coercitiva e agressiva. A identidade tradicional pode ser extinta e não traduzida (ALVAIDES, 2013).

O que ocorreu no PE Ilha do Cardoso e vem ocorrendo em PARNAs é o abandono da atividade de manejo de espécies vegetais (extrativismo e cultivo) e aumento da atividade turística. Segundo Toledo e Barrera-Bassols (2015) o abandono de práticas de manejo, como de plantas medicinais ou alimentícias, pode ao longo do tempo promover a perda da memória biocultural dessas populações, desencadeando na extinção de práticas culturais que também deveriam ser focos de práticas conservacionistas.

Problemas relativos a presença de pessoas em áreas protegidas registrados neste estudo, são comuns em praticamente todos os países da América Latina, África e Ásia (ARRUDA, 1999) sendo um dos temas mais discutido entre os órgãos 
governamentais, não governamentais e de pesquisas cientificas. Para AvellanedaTorres et al. (2015) os conflitos entre comunidades e a gestão de áreas protegidas são recorrentes em países em desenvolvimento, pois em geral estas áreas estão inseridas numa matriz rural, onde existe alta concentração de terras nas mãos de poucas pessoas, e uma imensa maioria de pequenos agricultores sem terras ou com terrenos muito reduzidos. Esta discussão é suportada pelos dados de Madeira et al. (2015) que evidenciaram a presença de pequenos agricultores e assentados de reforma agrária dentro dos PARNAs no Brasil. Assim para Avellaneda-Torres et al. (2015) a origem dos conflitos está fora das áreas protegidas, e estes poderiam ser solucionados ou minimizados pela revisão das políticas de distribuição de terras, evitando a exclusão das populações humanas dos processos conservacionistas.

Ferreira (2004) afirma que a resolução dos conflitos pode ser promovida pelo diálogo e estabelecimento de pactos sociais entre as unidades e as comunidades, independente do reconhecimento da tradicionalidade, de modo a identificar as populações que representam potenciais parceiros na conservação.

A pesquisa realizada por Scalco e Gontijo (2017) na porção central do Mosaico do Espinhaço em Minas Gerais, mostrou que a melhor alternativa para as comunidades tradicionais é a flexibilização por meio de acordos, pactos ou Termos de Compromisso, evitando perdas maiores como a desafetação, redução de limites ou recategorização da área protegida. Isso poderia ser seguido pelos PARNAS que afirmaram possuir populações residentes e que não apresentavam nenhum tipo de acordo com as mesmas. Para Chicchón (2000), além de evitar conflitos socioambientais, o bom relacionamento entre a gestão e as populações residentes melhora a conservação do local e valoriza o conhecimento tradicional, beneficiando, portanto, ambas as partes.

Sendo assim, considerando as dificuldades em relação aos recursos humanos e financeiros para realização de realocação destas comunidades, os acordos formais se apresentam como uma ferramenta importante para a mediação de conflitos, pois, de acordo com Ferreira (2004) com diálogo entre gestores e comunidade é possível estabelecer "pactos sociais" que possam manter a subsistência econômica e cultural das populações residentes, quanto assegurar a conservação da UC.

Assim, o estabelecimento destes acordos ou pactos sociais, e o cumprimento dos mesmos, levam a uma boa relação entre as populações e a administração, resultando em uma possível gestão compartilhada (KALIKOSKI; SEIXAS; ALMUDI, 2009). A gestão compartilhada pode ser definida como um processo que envolve os usuários e as comunidades locais, desde o planejamento das áreas até sua implantação e gestão, e onde os processos decisórios têm sua responsabilidade partilhada entre diferentes atores, como representantes do governo, das comunidades locais, entre outros (FREITAS et al., 2015). Segundo Irving (2014) o envolvimento das comunidades na gestão resulta em possíveis alternativas e ações para a melhoria da qualidade de vida dessas pessoas, fazendo com que a percepção destas populações sobre a área protegida possa se tornar positiva, diminuindo assim os conflitos entre a gestão e as pessoas residentes em áreas protegidas. 


\section{Considerações Finais}

Os resultados evidenciam a existência de conflitos entre a administração dos Parques e as populações residentes, pois os gestores(as) percebem a presença de comunidades humanas como um "problema" para a conservação nos PARNAs, e muitos dos gestores(as) não estão abertos ou não acreditam na possibilidade de diálogos e acordos.

No entanto, considerando as dificuldades de realocação dessas comunidades, a falta de recursos do Estado para promover as indenizações, além de possíveis consequências negativas para as populações, um caminho para a minimização dos conflitos entre a gestão e as populações residentes seria a promoção de diálogos e a tentativa de estabelecimento de acordos. Estes acordos deveriam evidenciar as atividades permitidas dentro de uma UCPI e atividades que deveriam ser restringidas, de modo a possibilitar a permanência das comunidades dentro de normas acordadas entre todos atores envolvidos.

Estes acordos, se construídos de forma participativa tendem a ser seguidos pelas comunidades residentes e poderiam se caracterizar como um passo na construção de uma gestão compartilhada integrando a presença das comunidades na gestão das áreas protegidas, o que poderia garantir a sobrevivência dessas comunidades e de seus saberes, além da conservação da Natureza e da biodiversidade que é o objetivo primário dos Parques Nacionais.

\section{Agradecimentos}

Os autores agradecem ao ICMBio pela autorização da pesquisa e a todos gestores e gestoras do PARNAS que responderam a entrevista, contribuindo assim para realização desta pesquisa.

\section{Referências}

ARAUJO, M. A. R. Unidades de Conservação no Brasil: da República à Gestão de Classe Mundial. Belo Horizonte: Editora SEGRAC, 2007. 272 p.

ARNELL, A. et al. Contribution of Protected Areas to Goal C. Protected Planet Report. In: BHOLA, N. et al. (Orgs.). Protected Planet Report 2016: How protected areas contribute to achieving global targets for biodiversity. Cambridge UK and Gland, Switzerland.: UNEP-WCMC and IUCN, 2016, p. 30-42.

ARRUDA, R. S. V. "Populações Tradicionais" e a proteção dos recursos naturais em Unidades de Conservação. Ambiente \& Sociedade, São Paulo,v. 2, n. 5, p.79-93, 1999.doi: 10.1590/S1414-753X1999000200007.

ALVAIDES, N. Tradições traduzidas: Um estudo psicossocial sobre as memórias sociais dos moradores da comunidade do Marujá - Parque Estadual da llha do Cardoso. Dissertação (Mestrado em Psicologia) - Universidade Federal de São Carlos. São Carlos, p. 178. 2013.

AVELLANEDA-TORRES, L. M.; ROJAS, E. T.; SICARD, T. E. L. Alternativas ante el conflicto entre autoridades ambientales y habitantes de áreas protegidas en páramos colombianos. Mundo Agrario, v. 16, n. 31, 2015. Disponível em: <https://www. mundoagrario.unlp.edu.ar/article/view/MAv16n31a11>. Acesso em: fev. 2018. 
BARRETO FILHO, H. T. (2014). Gestão Ambiental e Territorial: um panorama dos espaços territoriais especialmente protegidos no Brasil. In: LITTLE, P. E. (Org.). Os novos desafios da política ambiental brasileira. Brasília: IEB, p. 274-302, 2014.

BRASIL. Lei no 9.985, de 18 de julho de 2000. Regulamenta o Art. 225, incisos I, II, III e VII da Constituição Federal, instituindo o Sistema Nacional de Unidades de Conservação da Natureza (SNUC). Brasília: DOU de 19/7/2000.

BRASIL. Decreto no 6.040, de 7 de fevereiro de 2007. Institui a Política Nacional de Desenvolvimento Sustentável dos Povos e Comunidades Tradicionais. Brasília: DOU de $8 / 2 / 2007$.

BRASIL. Lei no 11.516, de 28 de agosto de 2007. Dispõe sobre a criação do Instituto Chico Mendes de Conservação da Biodiversidade - Instituto Chico Mendes. Brasília: DOU de 28/8/2007.

BRASIL. Instrução Normativa no 26, de 4 de julho de 2012. Estabelece diretrizes e regulamenta os procedimentos para a elaboração, implementação e monitoramento de termos de compromisso. Brasília: DOU de 6/7/2012.

BRITO, D. M. C. Conflitos em unidades de conservação. PRACS: Revista Eletrônica de Humanidades do Curso de Ciências Sociais da UNIFAP, Amapá, v. 1, n. 1, p. 1-12, 2008.

BRITO, M. C. W. Unidades de Conservação: intenções e resultados. São Paulo: Editora Annablume,2000. 230 P.

CAMPOLIM, M. B.; PARADA, I. L. S.; YAMAOKA, J. G. Gestão participativa da visitação publica na comunidade do Marujá- Parque Estadual da Ilha do Cardoso. IF Sér. Reg, São Paulo, n. 33, p. 39-49, 2008.

CHICCHÓN, A Conservation theory meets practice. Conservation Biology, v. 14, n. 5, p. 1368-1369, 2000.doi: 10.1046/j.1523-1739.2000.00200

DIEGUES, A. C. S. (Org). Etnoconservação: novos rumos para a proteção da natureza nos trópicos. São Paulo: HUCITEC/ANNABLUME/NAPAUB-USP, 2. ed., 2000. 290p.

DIEGUES, A. C. S.; ARRUDA, R. S. V. (Orgs.). Os Saberes tradicionais e a biodiversidade no Brasil. Brasília: Ministério do Meio Ambiente; São Paulo: USP, 2001. 211 p.

DIEGUES, A. C. S. O mito moderno da natureza intocada.São Paulo: HUCITEC/ANNABLUME/NAPAUB-USP, 5. ed2004. 169 p.

DRUMMOND, J. A.; DIAS, T. C. A. C.; BRITO, D. M. C. Atlas das Unidades de Conservação do Estado do Amapá. Macapá: MMA/IBAMA-AP;GEA/SEMA, 2008. $128 \mathrm{p}$.

DUDLEY, N. (Org.). Guidelines for Applying Protected Area Management Categories. Gland, Switzerland: IUCN. 2008. Disponível em: <https://portals. iucn.org/library/sites/library/files/documents/PAPS-016.pdf>.Acesso em: jan. 2018.

FERREIRA, L. C; Dimensões humanas da biodiversidade: mudanças sociais e conflitos em torno de áreas protegidas no Vale do Ribeira, SP, Brasil. Ambiente \& Sociedade, São Paulo, v. 7, n. 1, p. 47-66, 2004. 
FRANCO, J. L. A.; SCHITTINI, G. M.; BRAZ, V. S. História da conservação da natureza e das áreas protegidas: Panorama geral. Historiæ, Rio Grande, v. 6, n. 2,p. 233-270, 2015.

FREITAS, R.R..; GERHARDINGER, L.C.; COSTA, P.C.P.; SEIXAS, C.S. Governança dos Oceanos na Rio+20: o debate sobre Áreas Marinhas Protegidas na perspectiva da gestão compartilhada. In: CASTRO, F.; FUTEMMA, C. (Orgs.) Governança Ambiental no Brasil: entre o socioambientalismo e a Economia Verde. Jundiaí. Paco Editorial, 2015.

IRVING, M. DE A. Governança democrática e gestão participativa de áreas protegidas: um caminho sem volta para a conservação da biodiversidade no caso brasileiro. In: BENSUSAN, N.; PRATES, A. P. (Orgs.). A diversidade cabe na unidade? áreas protegidas no Brasil. Brasília: IEB, p. 167-182, 2014.

KALIKOSKI, D. C.; SEIXAS, C. S.; ALMUDI, T. Gestão compartilhada e comunitária da pesca no Brasil: avanços e desafios. Ambiente \& Sociedade, Campinas, v. 12, n. 1, p. 151-172, 2009.

LITTLE, P. E. Territórios Sociais e povos tradicionais no Brasil: por uma antropologia da territorialidade. Universidade de Brasília, Série Antropologia, n. 322, 2002.

MADEIRA, J. A. et al. Interfaces e Sobreposições entre Unidades de Conservação e Territórios de Povos e Comunidades Tradicionais: Dimensionando o Desafio. ICMBio, 2015. Disponível em: $<$ http://www.icmbio.gov.br/portal/images/stories/o-que-fazemos/gestao-socioambien tal/DCOM interfaces e sobreposicoes entre ucs e territorios de povos e comunidades tradicionais dimensionando o desafio.pdf >. Acesso em: set. 2019.

OLIVEIRA, E. R. Populações Humanas na Estação Ecológica de Juréia- Itatins. NUPAUB-USP: Série documentos e relatórios de pesquisa: n. 2, 2004. Disponível em: <http://www.usp.br/nupaub/jureiaitatins.pdf> Acesso em: jan. 2018.

PEREIRA, B.; DIEGUES, A. C. Conhecimento de populações tradicionais como possibilidade de conservação da natureza: uma reflexão sobre a perspectiva da etnoconservação. Desenvolvimento e Meio Ambiente, v. 22, p. 37-50, 2010.

PEREIRA, M. A, et al. The collective action on governing the commons in the surroundings of protected areas. Ambiente \& Sociedade, São Paulo v. 19, n. 4, p. 21-38, 2016.

REDFORD, K.; RICHTER, B. Conservation of biodiversity in a world of use. Conservation Biology, v. 13, n. 6, p. 1246-1256, 2001.

SCALCO, R. F.; GONTIJO, B. M. Possibilidades de desafetação e recategorização em Unidades de Conservação de Proteção Integral: as UCS da porção Central do Mosaico do Espinhaço (Minas Gerais/Brasil). Revista da Associação Nacional de Pós-graduação e Pesquisa em Geografia (Anpege), v. 13, n. 22, p. 247-276, 2017.

SILVA PIMENTEL, M. A.; RIBEIRO, W. C. POPULAÇÕES tradicionais e conflitos em áreas protegidas. Geousp - Espaço e Tempo (Online), v. 20, n. 2, 224-237, 2016.

SILVEIRA-JUNIOR, W. J.; BOTELHO, E. S. Turismo em áreas protegidas e inclusão social de populações tradicionais: um estudo de caso da Cooperativa de Ecoturismo de Guaraqueçaba (PR). Revista Brasileira de Ecoturismo, v. 4, n. 3, p. 441-462, 2011. 
TERBORGH, J. et al. Tornando os Parques Eficientes: Estratégias para a Conservação de Natureza nos Trópicos. Curitiba: Editora UFPR, Fundação O Boticário de Proteção à Natureza, 2002. 518 p.

TOLEDO, V. M.; BARRERA-BASSOLS, N. A Memória Biocultural: a importância ecológica das sabedorias tradicionais. São Paulo: Editora Expressão Popular, 1. Ed., 2015. 272 p.

Aline Francisco Damasceno: Universidade Federal de São Carlos, Sorocaba, SP, Brasil

E-mail: alinedamascenopolly@hotmail.com

Link para o currículo Lattes: http://lattes.cnpq.br/9323301617650758

Gabriela Ferreira Mylonas: Universidade Federal de São Carlos, Sorocaba, SP, Brasil

E-mail: gabriela.precog@hotmail.com

Link para o currículo Lattes: http://lattes.cnpq.br/5145808155627106

Eliana Cardoso-Leite: Universidade Federal de São Carlos, Sorocaba, SP, Brasil

E-mail: cardosoleite@yahoo.com.br

Link para o currículo Lattes: http://lattes.cnpq.br/2186623269243747

Data de submissão: 12 de março de 2019

Data de recebimento de correções: 26 de março de 2019

Data do aceite: 26 de março de 2019

Avaliado anonimamente 